\title{
INTERFERÊNCIA DA COMPACTAÇÃO DO SOLO NO MANEJO DE ALTAS PRODUTIVIDADES NA CULTURA DA SOJA
}

\author{
MOURA, Jean Carlos \\ BARBOSA, Márcia Aparecida Borges \\ CARDOSO, Saulo Strazeio ${ }^{1}$
}

\begin{abstract}
RESUMO: A demanda mundial por alimentos é constante, assim como a busca por novas tecnologias na cultura da soja. A construção do perfil de solo para altas produtividades é primordial. A produtividade é definida pela interação entre planta, ambiente de produção e manejo adequado. A compactação é um processo de degradação física dos solos que interfere no desempenho das lavouras e na produção de grãos. Para obter produtividades mais elevadas, os valores de resistência (RS) devem estar abaixo de 1,70 MPa até a camada de $30 \mathrm{~cm}$ e menores que 1,6 e 1,5 MPa na camada entre 40 e $50 \mathrm{~cm}$. A escarificação pode ser uma alternativa, após um diagnóstico confirmando as áreas compactadas. Maiores rendimentos de grãos de soja foram observados após a escarificação biológica do solo isolada ou associada ao uso do escarificador. Solos com boas qualidades físicas propiciam melhor aproveitamento pelas raízes promovendo um melhor desempenho da cultura. Independente do sistema de cultivo, a compactação é um processo inerente, isso ocorre em decorrência de vários motivos. Para alcançar altas produtividades são necessários monitoramentos destes impedimentos físicos, e a aplicação de manejo adequado. O objetivo geral deste trabalho foi identificar a interferência de uma das principais variáveis que podem afetar a produtividade de soja, mediante a um estudo exploratório multidisciplinar através de investigações que se deram por meio de pesquisas bibliográficas avaliando qual a relação que a compactação do solo exerce nas produtividades de soja.
\end{abstract}

Palavras-chave: Agricultura. Escarificador. Mecanização.

\section{INTERFERENCE OF SOIL COMPACTION IN THE MANAGEMENT OF HIGH GRAIN YIELD IN SOYBEAN CROP}

\begin{abstract}
SUMMARY: The global demand for food is constant, as is in the search for new technologies in the soybean crop. The construction of the soil profile for high grain yield is essential, grain yield is defined by the interaction between plant, production environment and adequate management. Compaction is a process of soil physical degradation that interferes with crop performance and grain production. To obtain higher yields, the resistance values (RS) must be below $1.70 \mathrm{MPa}$ up to the $30 \mathrm{~cm}$ layer and less than 1.6 and $1.5 \mathrm{MPa}$ in the layer between 40 and $50 \mathrm{~cm}$. Scarification may be an alternative, after a diagnosis confirming the compacted areas. Higher yields of soybean grains were observed after the soil biological scarification isolated or associated to the use of the scarifier. Soils with good physical qualities propitiate better utilization by the roots propitiating a better performance of the culture. Regardless of the cropping system, compaction is an inherent process, this occurs due to several reasons, in order to achieve high grain yield, it is necessary to monitor these physical impediments, and to apply appropriate management. The general objective of this work was to identify the interference of one of the main variables that can affect the soybean grain yield, through a multidisciplinary exploratory study through investigations that have been done through bibliographical research evaluating the relation that soil compaction exerts in the soy productivities.
\end{abstract}

Keywords: Agriculture. Scarifier. Mechanization.

\section{INTRODUÇÃO}

A cultura da soja (Glycine max) é a principal cultura da agricultura brasileira, devido ao seu potencial produtivo, composição química e valor nutritivo (MAUAD et. al., 2010). O USDA (United

\footnotetext{
${ }^{1}$ FCAV - Unesp Jaboticabal
} 
States Department of Agriculture) estimou uma produção mundial de 336 milhões de toneladas de soja, na safra 2017/2018, e o Brasil é responsável por aproximadamente um terço dessa produção (116,9 milhões de toneladas) em uma área de 35 milhões de hectares (EMBRAPA SOJA, 2018).

Do total da produção brasileira, 59 milhões de toneladas são consumidos internamente e o restante é exportado (CONAB, 2018). Em torno de 68 milhões de toneladas são exportadas in natura, 14 milhões de toneladas são exportadas como farelo de soja e 1,3 milhão de tonelada é exportada como óleo (EMBRAPA SOJA, 2018).

Na safra 2017/2018, a estimativa é de 35,1 milhões de hectares, sendo 3,6\% superior ao cultivado na safra 2016/17 (CONAB, 2018).

$\mathrm{Na}$ agricultura moderna a expansão da mecanização impõe altas pressões no solo, devido ao intenso tráfego de máquinas. Estes fatores contribuem para a degradação da qualidade física do solo (MULLER et al., 2014).

Para Kertzman (1996), a compactação do solo é um termo que se refere a processos mecânicos, induzidos pela ação antrópica, que modifica a estrutura causando alterações físicas, químicas e biológicas, pelo comportamento da água e do ar no solo, afetando diretamente o crescimento das raízes.

A compactação do solo interfere diretamente no desempenho das lavouras, resultando na perda de estabilidade estrutural e diminuição dos macro e microporos, aumentando a resistência do solo (CUNHA et al., 2012), causando alterações, deixando o ambiente físico desfavorável ao crescimento radicular e ao desenvolvimento da cultura (GIAROLA et al., 2007).

Segundo Barros, (2017) áreas sob o sistema de plantio direto no Cerrado vêm sofrendo com o processo de compactação, sendo perceptível por alterações nos atributos físicos do solo e na redução de produtividade das culturas.

Com isso, a busca por valores que indiquem as restrições ao crescimento das raízes interferindo nas produtividades, torna-se cada vez maior para o sucesso da exploração agrícola (MONTANARI et al., 2013).

O objetivo geral deste trabalho foi identificar a interferência de uma das principais variáveis que podem afetar a produtividade de soja, mediante a um estudo exploratório multidisciplinar através de investigações que se deram por meio de pesquisas bibliográficas avaliando qual a relação que a compactação do solo exerce nas produtividades de soja.

\section{DESENVOLVIMENTO}

Solos de altas produtividades podem ser definidos como solos de fertilidade construída, com manejo ao longo do tempo, com condições físicas, biológicas e químicas ideais para as culturas (KAPPES; ZANCANARO, 2014).

O conhecimento do perfil do solo e seus atributos são ferramentas de grande importância para aperfeiçoar o manejo em áreas agrícolas, com um gerenciamento correto das informações pontuais de cada solo (AMADO et al., 2009).

Para Guadagnin et al. (2005) o plantio direto promoveu benefícios ao sistema, como: diminuição da perda de água por escorrimento superficial, menor perda de solo e nutrientes por erosão, isso contribuiu no incremento da produção de grãos no Brasil.

A contribuição principal do plantio direto está ligada à adição de matéria orgânica ao sistema, melhorando relativamente às propriedades edáficas (CARDOZO et al., 2008). Além dos benefícios, tem- se observado no plantio direto a ocorrência de compactação nas camadas superficiais do solo 
(BERTOL et al., 2004).

No plantio direto não temos o revolvimento intensivo do solo comparado ao plantio convencional, com isso, associado ao tráfego intensivo de máquinas na área e a maior umidade do solo, podem ocorrer a compactação do solo (BARROS, 2017). A compactação segundo Goedert et al. (2002), traz efeitos negativos como: aumento da resistência mecânica ao crescimento radicular, redução da aeração, menor disponibilidade de água e nutrientes.

Com a redução da taxa de infiltração de água no solo (LANZANOVA et al., 2007), e redução de elementos no solo, o desenvolvimento das culturas é afetado, por conta das alterações nos processos químicos e biológicos (CAMARGO; ALLEONI, 1997). De acordo com Pereira et al. (2010), as alterações físicas podem influenciar em muitos fenômenos importantes do solo: quantidade de calor, água e gases transportados e resistência a penetração.

O tráfego intenso de máquinas como já mencionado, pode alterar as estruturas físicas do solo, comprometendo, assim, as produtividades agrícolas (ASSIS et al., 2009). Assim como o trafego de máquinas, a pecuária também pode causar alterações físicas no solo (FIGUEIREDO et al., 2009). A alta intensidade de animais na palhada pode prejudicar a produção agrícola, devido à maior compactação superficial do solo (VEIGA et al., 2014).

Porém, Moreira et al. (2012), após avaliar oito anos de integração lavoura pecuária, não confirmaram a hipótese de que o aumento do pisoteio animal diminui a qualidade física do solo. Contudo, no plantio direto a rotação de culturas é o manejo mais adequado, que por meio dos sistemas radiculares das diferentes espécies, auxiliam na estruturação do solo, além de propiciar o acúmulo de palhada (BARROS, 2017). Segundo Santos et al. (2011) são escassos trabalhos de longa duração que permitam observar as alterações na qualidade do solo, resultantes dos efeitos acumulados dos sistemas de manejo.

A resistência à penetração do solo é uma propriedade física que influencia diretamente o crescimento de raízes (TAVARES FILHO; RIBON, 2008). Além de proporcionar restrição ao crescimento radicular, a compactação, afeta a infiltração (LANZANOVA et al., 2007); assim como a condutividade hidráulica, causando perdas diretas nas produtividades (CAMARGO; ALLEONI, 1997).

A degradação da estrutura do solo pode interferir na produtividade das culturas, reduzindo a porosidade total, e a infiltração de água no solo (LOURENTE et al., 2011).

A resistência à penetração tem sido utilizada em aplicações de diversas áreas de pesquisa agronômica, tais como: detecção de camadas compactadas, interferência no desenvolvimento do sistema radicular das plantas, entre outros (CUNHA et al., 2002).

Para Henderson (1989) a resistência à penetração deve ser medida com a umidade próxima à capacidade de campo, situação está com boa correlação entre a densidade do solo, a resistência à penetração e o crescimento radicular.

Valores críticos de resistência à penetração podem variar de 1,5 MPa a 4,0 MPa (ROSOLEM et al., 1999); assim também Tavares Filho e Tessier (2009), detectaram que valores de resistência a penetração entre 2,0 a 4,0 MPa, podem restringir, ou mesmo impedir, o crescimento e desenvolvimento das raízes, valores estes que são mais prejudiciais em solos secos.

Geralmente, tem-se adotado o valor da resistência a penetração de 2,0 MPa como crítico ao crescimento radicular (TORMENA et al., 1998); no entanto, valores próximos a 2 MPa são, de maneira geral, aceitos como impeditivos ao crescimento radicular (BLAINSKI et al., 2008).

A camada compactada é quantificada pelos valores de resistência à penetração e concluíram que valores de resistência a penetração acima de 2,5 MPa restringem o crescimento das raízes (CAMARGO; ALLEONI, 1997). De acordo com Bennie et al. (1996) valores acima de 1 MPa já inicia um decréscimo de crescimento radicular, e acima de $2 \mathrm{MPa}$ as raízes perdem de $60 \%$ a $80 \%$ do seu 
potencial de crescimento.

Segundo Zou (2001) quando o solo atinge $2 \mathrm{MPa}$ o crescimento radicular cai pela metade; já para Beutler et al. (2007) a redução na produtividade de grãos em solos com resistência a penetração ocorre no intervalo entre 1,30 e 1,64 MPa para a cultura da soja.

Mahl et al. (2008) relatam que o sistema de plantio direto, admite valores mais altos de resistência do solo à penetração. Em condições de umidade ideal pode haver crescimento radicular em valores superiores a 4,0 MPa (TAVARES FILHO; TESSIER 2009).

De acordo com Betioli Jr et al. (2012) em muitas áreas com elevados valores de densidade (acima de $2 \mathrm{MPa}$ ) não houve redução da produtividade de grãos e nem do crescimento radicular.

Contudo, Santos (2010) relata em seu trabalho a maior dificuldade de encontrar um índice exato que inclua os atributos físicos do solo e que se relacione com crescimento, desenvolvimento e produção das plantas.

A resistência física à penetração que o solo submete as raízes em crescimento, tem grande influência sobre a produtividade nas culturas, uma vez que, a produtividade das culturas e o crescimento radicular variam de forma inversamente proporcional ao valor de resistência à penetração (LIMA et al.,2010; TOIGO et al., 2015).

Busscher et al. (2000) afirma que no manejo de altas produtividades para cada $1 \mathrm{MPa}$ de resistência que se aumenta há o decrescimento linear de $12 \mathrm{scs} \mathrm{ha}^{-1}$ de soja. Em trabalho com produtividade entre 46 a $53 \mathrm{scs} \mathrm{ha}^{-1}$, Lima et al., (2010), identificou que valores em 1,9 MPa se mostraram limitantes na produtividade.

Segundo Sako et al. (2016), para produtividades maiores que $70 \mathrm{scs} \mathrm{ha}^{-1}$ os valores são menores, o que reforça a importância no monitoramento do impedimento físico do solo em altas produtividade de soja, assim quanto maior a resistência do solo menor a produtividade.

Para Girardello et al. (2011) é recomendado o processo de escarificação somente onde a compactação foi realmente diagnosticada. Assim deve-se utilizar um sistema de manejo que consiga romper esta camada compactada, mobilizando o mínimo possível a camada arável e mantendo o máximo de palha sobre o solo (CARVALHO FILHO et al., 2007).

A escarificação esporádica do solo, segundo Reichert et al. (2009) tem sido eficiente em reduzir os efeitos imediatos na compactação do solo. Pesquisas vêm sendo realizadas para avaliar a eficiência da escarificação mecânica, seus efeitos sobre a compactação do solo e sua longevidade (BARROS, 2017).

Em áreas onde foi utilizado escarificadores mecânicos, houve redução nos valores de resistência do solo, confirmando a eficiência do manejo (GIRARDELLO et al., 2014). No entanto, na maioria das vezes, o efeito da descompactação é temporário e, após apenas um ano, o solo volta ao estado original de compactação (NICOLOSSO et al., 2008).

Foi avaliando o tempo de duração de escarificação mecânica em sistema plantio direto, que (DRESCHER et al., 2016)., observaram menor resistência a penetração em até 18 meses após a escarificação. Para Secco e Reinert (1997) a escarificação mecanizada têm um efeito residual apenas de 10 meses após a operação.

A escarificação do solo não proporciona melhoria efetiva e duradoura à estrutura de solos argilosos sob plantio direto (NUNES et al., 2014). Assim também Nicolosso et al. (2008), verificaram que a escarificação mecânica como método isolado de descompactação não favoreceu a infiltração de água no solo. O curto período de eficiência da escarificação mecânica tem relação com a forma de atuação das hastes, que deixam agregados compactos nos espaços entre as hastes, assim favorece o rápido retorno à condição anterior à escarificação, já após o primeiro ano de cultivo (MORAES, 2013). 
A escarificação biológica aumentou a persistência da melhoria das condições físicas do solo induzidas pela escarificação mecânica (NICOLOSSO et al., 2008). Com isso a escarificação biológica é uma boa opção com o uso de plantas com sistema radicular profundo e robusto, capaz de crescer em camadas de solo compactado (ABREU et al., 2004).

O consórcio de nabo-forrageiro e aveia-preta em semeadura direta, ou após a escarificação mecânica do solo, aumentou significativamente a lâmina de água infiltrada no solo (NICOLOSSO et al., 2008).

Plantas de cobertura vêm sendo utilizadas como alternativas para rotação de culturas, melhorando o potencial produtivo, e contribuindo para a melhoria dos atributos físicos, químicos e biológicos do solo (CALEGARI et al., 2014).

Conforme estudos relatados por Cardoso et al. (2014), o cultivo em sucessão as plantas de cobertura, vem obtendo respostas positivas nas produtividades de soja.

Segundo estudos realizados por Sanchez (2012) e Wolschick (2014), não observaram diferenças estatísticas do cultivo de soja em sucessão as plantas de cobertura. Fato este, que pode ter ocorrido devido ao experimento ser realizado apenas em uma safra, portanto, não houve tempo para a decomposição da matéria orgânica (HENZ; ROSA, 2017).

Sendo assim, cada vez mais se verifica a importância de pesquisas de campo com maior duração, onde possa identificar qual o nível real de compactação, que vai interferir diretamente no rendimento da cultura da soja, e quais os manejos mais adequados para cada ocasião (MAZURANA et al., 2011).

\section{CONCLUSÃO}

Pelo presente estudo pode-se concluir que: todos os sistemas de cultivo provocam alguma alteração nos atributos físicos e biológicos do solo, sendo a compactação um processo inerente na produção agrícola em decorrência de vários motivos relatados neste trabalho, sendo fundamental a análise quantitativa e qualitativa para detectar as mudanças na qualidade do solo sob cultivo.

A escarificação mecânica pode ser uma alternativa, após um diagnóstico confirmado das áreas compactadas acima de $2 \mathrm{MPa}$, associando a escarificação biológica do solo com plantas de cobertura que possua sistema radicular robusto no prazo máximo 12 meses.

O sistema de plantio direto é uma excelente alternativa de manejo, podendo amenizar a compactação através da rotação de culturas e pelo acúmulo de matéria orgânica no solo. Embora de extrema importância, torna-se difícil esse tipo de pesquisa haja visto que cada solo possui uma combinação de textura e estrutura distintos. Para cada combinação há um valor específico para a limitação. Se acrescentarmos a planta dentre os fatores, essa combinação aumenta mais, pois estaremos fazendo uma combinação de textura, estrutura e planta.

\section{REFERÊNCIAS}

ABREU, S. L.; REICHERT, J. M.; REINERT, D. J. Escarificação mecânica e biológica para a redução da compactação em Argissolo franco-arenoso sob plantio direto. Revista Brasileira de Ciência do Solo, Viçosa, v. 28, n. 3, p. 519-531, 2004.

AMADO, T. J. C.et al. Atributos químicos e físicos de Latossolos e sua relação com os rendimentos de milho e feijão irrigados. Revista Brasileira de Ciência do Solo, v. 33, n. 4, p. 831-843, 2009. 
ASSIS, R, I.et al. Avaliação da resistência do solo à penetração em diferentes solos com a variação do teor de água. V. 29 , p. $558-568.2009$.

BARROS, L. R. Escarificação e gessagem na descompactação do solo sob sistema plantio direto. 2017. 62 f. Dissertação (Mestrado em Agronomia: Solo e Água) - Escola de Agronomia, Universidade Federal de Goiás, Goiânia, 2017.

BENNIE, A.T.P. Growth and mechanical impedance. In: WAISEL, Y.; ESHEL, A. ; KAFKAFI, U., eds. Plant roots. 2.ed. New York, M. Dekker, p.453-470. 1996.

BETIOLI JÚNIOR, E.; MOREIRA, W. H.; TORMENA, C. A.; FERREIRA, C. J. B.; SILVA, A. P. ; GIAROLA, N. F. B. Intervalo hídrico ótimo e grau de compactação de um Latossolo Vermelho após 30 anos sob plantio direto. Revista Brasileira de Ciência do Solo, 36:971-982, 2012.

BERTOL, I.et al. Propriedades físicas do solo sob preparo convencional e semeadura direta em rotação e sucessão de culturas, comparadas às do campo nativo. Revista Brasileira de Ciência do Solo, v. 28, p. 155-163, 2004.

BEUTLER, A. N.et al. Intervalo hídrico ótimo no monitoramento da compactação e da qualidade física de um Latossolo Vermelho cultivado com soja. Revista Brasileira de Ciência do Solo, v.31, p.1223-1232, 2007.

BLAINSKI, E.et al. Quantificação da degradação física do solo por meio da curva de resistência do solo à penetração. Revista Brasileira de Ciência do Solo, v.32, p.975-983, 2008.

BUSSCHER, W. J.; FREDERICK, J. R.; BAUER, P. J. Timing effects of deep tillage on penetration resistance and wheat and soybean yield. Soil. Science Society of America Journal. v. 64, n. 3, 2000.

CALEGARI, A. Perspectivas e estratégias para a sustentabilidade e o aumento da biodiversidade dos sistemas agrícolas com o uso de adubos verdes. In: FILHO, O. F. L. et al. (Eds.). Adubação Verde e plantas de cobertura no Brasil: fundamentos e prática. Brasília: Embrapa, v. 1, cap. 1, p. 21-36. 2014.

CAMARGO, O. A.; ALLEONI, L. R. F. Compactação do solo e o desenvolvimento das plantas, Piracicaba, p. 132, 1997.

CARDOSO, R. A.et al. Influência da adubação verde nas propriedades físicas e biológicas do solo e na produtividade da cultura de soja. Seminário: Ciências Biológicas e da Saúde. Londrina, v. 35, n. 2, p. 51-60, jul/dez. 2014.

CARDOZO, S. V.et al. Caracterização de propriedades edáficas em áreas sob manejo orgânico e natural na região serrana do Estado do Rio de Janeiro. Seminário: Ciências Agrárias, v. 29, n. 3, p. 517-530, 2008 .

CARVALHO FILHO, A. et al. Métodos de preparo do solo: alterações na rugosidade do solo.

Engenharia Agrícola, v. 27, n. 1, p. 229-237, 2007.

CONAB. ACOMPANHAMENTO DA SAFRA BRASILEIRA DE GRÃOS. v. 5 - Safra 2017/18, n.9 Nono levantamento, junho 2018. ISSN: 2318-6852. Disponível em: < https://www.conab.gov.br/infoagro/safras >. Acesso em: 03 jul. 2018.

CUNHA, J. P. A. R.; VIEIRA, L. B.; MAGALHÃES, A. C. Resistência mecânica do solo à penetração sob diferentes densidades e teores de água. Engenharia na Agricultura, Viçosa, v.10, n.1-4, p.1-7, 2002.

CUNHA, E.Q.et al. Atributos físicos, químicos e biológicos do solo sob produção orgânica impactadas por sistemas de cultivo. Revista Brasileira Engenharia agrícola e ambiental. 16, 56-63, 2012. 
DRESCHER, M. S.et al. Duração das alterações em propriedades físico-hídricas de Latossolo argiloso decorrentes da escarificação mecânica. Pesquisa Agropecuária Brasileira, Brasília, v. 51, n. 2, p. 159$168,2016$.

EMBRAPA SOJA, EMPRESA BRASILEIRA DE PESQUISA AGROPECUÁRIA. 2018. Soja, disponível em: < https://www.embrapa.br/soja/busca-de-noticias/-/noticia/34910577/congressobrasileiro-de-soja-sera-aberto-com-conferencia-sobre-tendencias-do-mercado $>$. Acesso em: 09 jul. 2018.

FIGUEIREDO, C. C.et al. Propriedades físico-hídricas em Latossolo do Cerrado sob diferentes sistemas de manejo. Revista Brasileira de Engenharia Agrícola e Ambiental, v.13, p.146-151, 2009.

GIAROLA, N. F. B.; TORMENA, C. A.; DUTRA, A. C. Degradação física de um Latossolo Vermelho utilizado para produção intensiva de forragem. Revista Brasileira de Ciência do Solo. 31:863-873, 2007.

GIRARDELLO, V. C.et al. Alterações nos atributos físicos de um Latossolo Vermelho sob plantio direto induzidas por diferentes tipos de escarificadores e o rendimento da soja. Revista Brasileira de Ciência do Solo, Viçosa, v. 35, n. 6, p. 2115-2126, 2011.

GIRARDELLO, V. C.et al. Resistência à penetração, eficiência de escarificadores mecânicos e produtividade da soja em Latossolo argiloso manejado sob plantio direto de longa duração. Revista Brasileira de Ciência do Solo, Viçosa, v. 38, n. 4, p. 1234-1244, 2014.

GOEDERT, W. J. SCHERMACK, M. J. FREITAS, F. C. Estado de compactação do solo em áreas cultivadas no sistema de plantio direto. Pesquisa Agropecuária Brasileira, Brasília, v.37, n.2, p.223$227,2002$.

GUADAGNIN, J. C.et al. Perdas de solo, água e nitrogênio por erosão hídrica em diferentes sistemas de manejo. Revista Brasileira de Ciência do Solo, v. 29, p. 277-286, 2005.

HENDERSON, C.W.L. Using a penetrometer to predict the effects of soil compaction on the growth an yield of wheat on uniform, sandy soils. Australian Journal of Agricultural Research, Melbourne, v.40, n.3, p.497-508, 1989.

HENZ, F. M. ; ROSA H. A. Produtividade da soja após cultivo de plantas de cobertura de inverno. Revista Cultivando o Saber. ISSN 2175-2214. Edição Especial, p. 204 - 212. 2017.

KAPPES, C.; ZANCANARO, L. Manejo da fertilidade do solo em sistemas de produção no Mato Grosso. In: CONGRESSO NACIONAL DE MILHO E SORGO, 3.; SIMPÓSIO SOBRE LEPDÓPTEROS COMUNS A MILHO, SOJA E ALGODÃO, 1., 2014, Salvador. Eficiência nas cadeias produtivas e o abastecimento global: palestras. Sete Lagoas: Associação Brasileira de Milho e Sorgo, p.358-381. 2014.

KERTZMAN, F. F. Modificações na estrutura e no comportamento de um latossolo roxo provocados pela compactação. 1996. 153 f. Tese (Doutorado em Geografia Física) Faculdade de filosofia, letras e ciências humanas do departamento da Universidade de São Paulo, São Paulo, 1996.

LANZANOVA, M.E.et al. Atributos físicos do solo em sistemas de integração lavoura-pecuária sob plantio direto. Revista Brasileira de Ciência do Solo, 31:1131-1140, 2007.

LIMA, C. L. R.et al. Produtividade de culturas e resistência à penetração de Argissolo Vermelho sob diferentes manejos. Pesquisa Agropecuária Brasileira v.45. n.1. 2010.

LOURENTE, E. R. P.et al.. Atributos microbiológicos, químicos e físicos desolo sob diferentes sistemas de manejo e condições de cerrado. Pesquisa Agropecuária Tropical, Goiânia, v. 41, n. 1, p. 20-28, 2011.

MAHL, D.et al. Resistência do solo à penetração, cobertura vegetal e produtividade do milho em plantio direto escarificado. Acta Scientiarum. Agronomy, v. 30, n. 5, p. 741-747, 2008. 
MALAVOLTA, E. Manual de nutrição mineral de plantas. São Paulo: Editora Agronômica Ceres Ltda., 638 p. 2006.

MAUAD, M.et al. Influência da densidade de semeadura sobre características agronômicas na cultura da soja. Revista Agrarian, Dourados, v.3, n.9, p.175-181, 2010.

MAZURANA, M., LEVIEN, R., MULLER, J., ; CONTE, O. Sistemas de preparo de solo: alterações na estrutura do solo e rendimento das culturas. Revista Brasileira de Ciência do Solo, Viçosa v. 35, n. 4, p. 1197-1206, 2011.

MONTANARI, R.et al. Correlação entre produção de feijão e atributos físicos de um Latossolo em Mato Grosso do Sul. Revista Ceres, Viçosa, v.60, n.6, p.772-784, 2013.

MORAES, M. T. Qualidade física do solo sob diferentes tempos de adoção e de escarificação do sistema plantio direto e sua relação com a rotação de culturas. Dissertação (Mestrado) - Universidade Federal de Santa Maria, Santa Maria. 205p. 2013.

MOREIRA, W. H.et al. Atributos físicos de um Latossolo Vermelho distroférrico em sistema de integração lavoura-pecuária. Revista Brasileira de Ciência do Solo, v.36, p.389-400, 2012.

MULLER, R.et al.Atributos associados ao grau de compactação do solo e sua correlação com a produção agrícola. Acta Iguazu, Cascavel, v. 3, n. 3, p. 131-137, 2014.

NICOLOSSO, R. S.et al. Eficiência da escarificação mecânica e biológica na melhoria dos atributos físicos de um latossolo muito argiloso e no incremento do rendimento de soja. Revista Brasileira de Ciências de Solo, v. 32, n. 4, p. 1723-1734, 2008.

NUNES, M. R.et al. Persistência dos efeitos da escarificação sobre a compactação de Nitossolo sob plantio direto em região subtropical úmida. Pesquisa Agropecuária Brasileira, Brasília, v.49, n.7, p.531539, jul. 2014. DOI: 10.1590/S0100-204X2014000700005

PEREIRA, S. A.et al. Análise de componentes principais dos atributos físicos de um Latossolo Vermelho distrófico típico sob pastagem e mata. Global Science and Technology, v.3, p.87-97, 2010.

REICHERT, J. M.et al. Variação temporal de propriedades físicas do solo e crescimento radicular de feijoeiro em quatro sistemas de manejo. Pesquisa Agropecuária Brasileira, Brasília, v. 44, n. 3, p. 310319, 2009.

SAKO, H.et al. Fatores decisivos para se obter produtividade de soja acima de $4.200 \mathrm{~kg} / \mathrm{ha}$. Circular Tecnica 2, Midia Eletronica, p. 01 - 10, 01 set. 2016. disponível em: <http://www.cesbrasil.org.br/wpcontent/uploads/2016/11/Circular-Tecnica-2.pdf >. Acesso em: 17 jul. 2018.

SANCHEZ, E. Propriedades físicas do solo e produtividade de soja em sucessão a plantas de cobertura de inverno. Guarapuava, 2012. Dissertação (Mestrado em Produção Vegetal). Universidade Estadual do Centro-Oeste. 2012.

SANTOS, G. G. Impacto de sistemas de integração lavoura pecuária na qualidade física do solo. Goiânia: UFG, 122p. Tese Doutorado. 2010.

SANTOS, G. G.et al. Qualidade física do solo sob sistemas de integração lavoura-pecuária. Pesquisa Agropecuária Brasileira, v.46, p.1339-1348, 2011.

SECCO, D. ; REINERT, D.J. Efeitos imediato e residual de escarificadores em Latossolo Vermelhoescuro sob PD. Eng. Agríc., 16:52-61, 1997.

TAVARES FILHO, J. ; RIBON, A.A. Resistência do solo à penetração em resposta ao número de amostras e tipo de amostragem. Revista Brasileira de Ciência do Solo, 32: 487-494, 2008. 
TAVARES FILHO, J.; TESSIER, D. Compressibility of oxisol aggregates under no-till in response to soil water potential. Revista Brasileira de Ciência do Solo, v.33, p.1525-1533, 2009.

TOIGO, S.et al. Atributos físicos de um Nitossolo Vermelho cultivado com trigo, em sistema plantio direto, submetido à compactação e escarificação. Engenharia na Agricultura, Viçosa, v.23, n.1, p.19-28, 2015.

TORMENA, C. A.; SILVA, A. P.; LIBARDI, P. L. Caracterização do intervalo hídrico ótimo de um Latossolo Roxo sob plantio direto. Revista Brasileira de Ciência do Solo, v.22, p.573-581, 1998.

VEIGA, M. da; BALBINOT JUNIOR, A. A.; OLIVEIRA, D. A. de. Soil physical attributes in forms of sowing the annual winter pasture and intervals between grazing. Revista Ciência Agronômica, v.45, p.896905, 2014. DOI: 10.1590/S1806-66902014000500005.

WOLSCHICK, N. H. Desempenho de plantas de cobertura e influência nos atributos do solo e na produtividade de culturas em sucessão. 2014. 93 f. Dissertação (Mestrado) - Curso de Ciência do Solo, Universidade do Estado de Santa Catarina, Lages, 2014.

ZOU, C.et al. Effects of soil air-filled porosity, soil matric potential and soil strength on primary root growth of radiata pine seedlings. PlantandSoil. v. 236 n.1 . 2001. 